\title{
Efeito do cloreto de cálcio na qualidade de abacaxi 'Pérola' minimamente processado ${ }^{(1)}$
}

\author{
Lucimara Rogéria Antoniolli(2), Benedito Carlos Benedetti( ${ }^{(2)}$ e Men de Sá Moreira de Souza Filho ${ }^{(3)}$
}

\begin{abstract}
Resumo - O objetivo deste trabalho foi avaliar os efeitos do cloreto de cálcio na qualidade do abacaxi 'Pérola' minimamente processado. Os tratamentos, arranjados em delineamento inteiramente casualizado e dispostos em esquema fatorial $3 \times 5$, consistiram das concentrações de $\mathrm{CaCl}_{2}$ e dos períodos de armazenamento, com três repetições. Frutos previamente sanitizados foram descascados mecanicamente, fatiados manualmente e imersos em solução de $\mathrm{CaCl}_{2}$ a $1 \%$ e a $2 \%$ e em água (controle), durante 30 segundos. As fatias foram acondicionadas em embalagens de polietileno tereftalato e mantidas à temperatura de $4 \pm 1{ }^{\circ} \mathrm{C}$ durante períodos de $0,3,6,9$ e 12 dias. A textura não foi influenciada por nenhum dos fatores estudados. Constatou-se menor atividade peroxidásica nos frutos tratados com $\mathrm{CaCl}_{2} 2 \%$. Quanto à coloração, a imersão em solução de $\mathrm{CaCl}_{2} 1 \%$ resultou em fatias mais escurecidas, com menor valor $\mathrm{L}^{*}$ e maior valor $\mathrm{a}^{*}$ ao final do período de armazenamento. A utilização de $\mathrm{CaCl}_{2} \mathrm{em}$ abacaxi 'Pérola' minimamente processado não proporciona efeitos benéficos na textura, e interfere negativamente na coloração da polpa do fruto.
\end{abstract}

Termos para indexação: Ananas comosus, cor, textura, vida de prateleira.

\section{Effect of calcium chloride on quality of fresh-cut 'Pérola' pineapple}

\begin{abstract}
The objective of this research was to evaluate the effects of calcium chloride on quality of freshcut 'Pérola' pineapple. The experimental design was a completely randomized in a $3 \times 5$ factorial scheme, and the treatments were represented by the $\mathrm{CaCl}_{2}$ concentration and storage time, each one with three replicates. Fruits were sanitized, peeled mechanically, sliced manually and dipped into water (control) and in $\mathrm{CaCl}_{2}$ solutions $(1 \%$ and $2 \%$ ) for 30 seconds. Slices were placed in polyethylene terephtalate packages and stored at $4 \pm 1^{\circ} \mathrm{C}$ during periods of $0,3,6,9$ and 12 days. Texture was not influenced by any of the studied factors. Smaller peroxidase activity in the samples submitted to $\mathrm{CaCl}_{2} 2 \%$ was verified. Fresh-cut pineapple slices dipped in $\mathrm{CaCl}_{2} 1 \%$ showed more browning, presenting smaller $\mathrm{L}^{*}$ value and larger $\mathrm{a}$ * value at the end of the storage period. The use of $\mathrm{CaCl}_{2}$ in fresh-cut 'Pérola' pineapple does not provide beneficial effects on the texture and interfere negatively on the flesh color of fruit.
\end{abstract}

Index terms: Ananas comosus, color, texture, shelf life.

\section{Introdução}

O abacaxi apresenta excelente qualidade organoléptica, decorrente do sabor e aroma

\footnotetext{
(1) Aceito para publicação em 25 de julho de 2003. Apoio Financeiro da Fapesp, Prodetab/Banco Mundial.

(2) Universidade Estadual de Campinas, Fac. de Engenharia Agrícola, Dep. de Pré-Processamento de Produtos Agropecuários, Caixa Postal 6011, CEP 13083-970 Campinas, SP. E-mail: 1rantoni@agr.unicamp.br, benedeti@agr.unicamp.br

(3) Embrapa-Centro Nacional de Pesquisa de Agroindústria Tropical, Caixa Postal 13761, CEP 60511-110 Fortaleza, CE. E-mail: sa@cnpat.embrapa.br
}

característicos (Botrel \& Abreu, 1994). As cultivares Smooth Cayenne e Pérola lideram o mercado brasileiro e esta última é bastante apreciada para o consumo in natura (Gonçalves, 2000).

Os frutos da cultivar Pérola apresentam polpa de coloração branco-pérola, muito suculenta e de sabor muito agradável, com valores de textura em torno de 2,4 kgf. Os teores de sólidos solúveis variam entre as porções do fruto; a região basal apresenta valores sempre superiores aos das regiões mediana e apical (Usberti Filho et al., 1999). Tais valores podem variar entre $13,10^{\circ}$ Brix e $15,10^{\circ}$ Brix em frutos maduros (Manica, 1999). A acidez total titulável varia entre $0,57 \%$ e $0,67 \%$, sendo expressa como porcentagem de ácido cítrico. $\mathrm{O} \mathrm{pH}$ da polpa se enquadra na faixa 
de 3,5 a 3,9. Entre os componentes vitamínicos, destaca-se o ácido ascórbico, com teores médios de 26,6 mg por $100 \mathrm{~g}$ de polpa (Usberti Filho et al., 1999). $\mathrm{A}$ atividade peroxidásica da polpa encontra-se em torno de 5.624 $\mathrm{UAE} \mathrm{g}^{-1}$ (Brito, 2001).

O tratamento de produtos hortícolas com baixas concentrações de sais de cálcio normalmente proporciona melhores propriedades de textura (Barret, 1998), em virtude da função deste cátion em ligar os componentes pécticos da parede celular. A protopectina, formada pela combinação entre pectina, celulose, hemicelulose e Ca, mantém uma forte coesão entre as células durante o crescimento do fruto, o que resulta em elevado grau de firmeza. No entanto, no transcorrer da maturação, o Ca é desprendido da protopectina, iniciando a solubilização da pectina. Além disso, duas enzimas atuam na modificação da textura. A poligalacturonase atua na despolimerização da cadeia, e a pectinametilesterase promove a desesterificação da cadeia do ácido galacturônico (Kluge et al., 1997), o que permite a ligação do Ca aos grupos carboxílicos livres, formando pontes entre os polímeros de pectina adjacentes (Barret, 1998). O pectato de Ca, formado pela interação Ca-pectina, proporciona maior rigidez à lamela média e parede celular (Poovaiah, 1986), maior resistência à ação da poligalacturonase (Buescher \& Hobson, 1982) e interfere positivamente na pressão de turgescência celular (Mignani et al., 1995).

A utilização de $\mathrm{CaCl}_{2} 1 \%$ manteve a qualidade de kiwis minimamente processados durante 10 dias de armazenamento sob temperatura de $1^{\circ} \mathrm{C}$ e $85 \%$ de umidade relativa (Carvalho \& Lima, 2002). Em melões 'Cantaloupe' foram observados maiores valores de firmeza no tratamento de imersão em solução de $\mathrm{CaCl}_{2} 5 \%$ quando comparados aos tratados com $\mathrm{CaCl}_{2} 2,5 \%$ e $1 \%$ (Luna-Guzmán et al. 1999).

Este trabalho teve como objetivo avaliar os efeitos do cloreto de cálcio na qualidade do abacaxi 'Pérola' minimamente processado.

\section{Material e Métodos}

Abacaxis 'Pérola', provenientes de Touros, RN, foram pré-selecionados e transportados à Embrapa-Centro Nacional de Pesquisa de Agroindústria Tropical, Fortaleza,
$\mathrm{CE}$, onde foram padronizados quanto ao tamanho e à coloração da casca, lavados com água corrente e detergente neutro, e sanitizados com hipoclorito de sódio $(\mathrm{NaOCl})$ $200 \mathrm{mg} \mathrm{L}^{-1}$, em tanque de aço inoxidável, com movimentação de água durante dois minutos. Em seguida, os frutos foram acondicionados em caixas de plástico previamente lavadas e higienizadas $\left(\mathrm{NaOCl} 200 \mathrm{mg} \mathrm{L}^{-1}\right)$ e armazenados em câmara refrigerada à temperatura de $12 \pm 1^{\circ} \mathrm{C}$ por aproximadamente 18 horas. Posteriormente, os frutos foram minimamente processados (MP), isto é, descascados com auxílio de um descascador pneumático, cortados manualmente em fatias de aproximadamente $1 \mathrm{~cm}$ de espessura, e tiveram o cilindro central removido.

$\mathrm{O}$ delineamento experimental foi o inteiramente casualizado e os tratamentos, dispostos em esquema fatorial $3 \times 5$, constituíram as concentrações de $\mathrm{CaCl}_{2}(0 \%$, $1 \%$ e $2 \%)$ e os períodos de armazenamento $(0,3,6,9$ e 12 dias), com três repetições. As amostras destinadas à caracterização inicial dos frutos foram retiradas imediatamente após o fatiamento e as destinadas à avaliação no tempo 0 foram coletadas após o tratamento de imersão.

As fatias foram acondicionadas em caixas de plástico perfuradas e submetidas ao tratamento de imersão, durante 30 segundos, em água (controle) e em solução de $\mathrm{CaCl}_{2}$ a $1 \%$ e a $2 \%$ com adição de $\mathrm{NaOCl} 20 \mathrm{mg} \mathrm{L}^{-1}$, à temperatura de $10^{\circ} \mathrm{C}$. Decorrido o tempo de imersão, as fatias permaneceram em repouso por aproximadamente dois minutos para drenagem do excesso de líquido. Em seguida, as fatias de abacaxi foram acondicionadas em embalagens de polietileno tereftalato (PET), previamente higienizadas $\left(\mathrm{NaOCl} 20 \mathrm{mg} \mathrm{L}^{-1}\right)$, e mantidas à temperatura de $4 \pm 1^{\circ} \mathrm{C}$ durante os períodos de armazenamento. Todo o processamento foi realizado em ambiente refrigerado, com temperaturas variando entre $12^{\circ} \mathrm{C}$ e $15^{\circ} \mathrm{C}$. Para evitar a contaminação cruzada, os equipamentos e utensílios utilizados foram higienizados com solução de $\mathrm{NaOCl}$ $200 \mathrm{mg} \mathrm{L}^{-1}$ e foram utilizadas luvas, máscaras e toucas descartáveis.

A cada três dias foram analisadas as seguintes variáveis: textura (kgf), determinada pelo valor de força máxima obtido em texturômetro; $\mathrm{pH}$, determinado por potenciometria em amostra triturada e homogeneizada; atividade da enzima peroxidase, expressa por unidades de atividade enzimática (UAE $\mathrm{g}^{-1} \mathrm{~min}^{-1}$ ) e determinada segundo método de Khan \& Robinson (1994) com modificações; cor, determinada com auxílio de colorímetro, cujos parâmetros $\mathrm{L}^{*} \mathrm{e} \mathrm{a}^{*}$, recomendados para maçã (Artés et al., 1998), foram utilizados na avaliação do escurecimento do fruto, por serem mais adequados na detecção da coloração amarronzada verificada em ensaios preliminares; teor de sólidos solúveis totais ( ${ }^{\circ}$ Brix), determinado por refratometria; acidez total titulável 
(porcentagem de ácido cítrico), determinada por meio da diluição de $1 \mathrm{~g}$ de amostra homogeneizada em $50 \mathrm{~mL}$ de água destilada, e posterior titulação automática com solução de $\mathrm{NaOH} 0,1 \mathrm{~N}$, até pH 8,10; teor de ácido ascórbico (mg por $100 \mathrm{~g}$ de polpa), determinado segundo método de Carvalho et al. (1990), que se baseia na redução do indicador 2,6-diclorobenzenoindofenol (DCFI) pelo ácido ascórbico.

Os dados foram submetidos à análise de variância com posterior estudo de regressão polinomial.

\section{Resultados e Discussão}

A textura da polpa não foi influenciada por nenhum dos fatores estudados durante 12 dias de armazenamento refrigerado, com valores oscilando entre 1,25 e 1,51 kgf (caracterização inicial: 1,50 kgf). A ineficiência do tratamento pode ser atribuída à insuficiente absorção do Ca pelo tecido, seja pelo tempo de imersão, seja pela própria estrutura da polpa do fruto. Izumi \& Watada (1994), de forma semelhante, observaram que os tratamentos com $\mathrm{CaCl}_{2}(0,5 \%$ e 1,0\%) não apresentaram efeito sobre a textura de cenoura MP cortada em fatias e "palitos", ao passo que a cenoura ralada apresentou concentração de $\mathrm{Ca}$ duas e três vezes superior à constatada na cenoura "palito" e na fatiada, respectivamente. Além disso, algum possível efeito do Ca pode ter sido mascarado pela existência de lóculos na polpa, o que provavelmente interferiu na determinação da textura do fruto, no presente trabalho.

$\mathrm{O}$ tratamento com $\mathrm{CaCl}_{2}$ proporcionou valores de $\mathrm{pH}$ estatisticamente inferiores ao do controle, não havendo diferença significativa entre as concentrações utilizadas (Figura 1). Comportamento semelhante foi observado por Izumi \& Watada (1994) em cenoura ralada submetida ao tratamento com $\mathrm{CaCl}_{2} 1 \%$ com ou sem adição de $\mathrm{NaOCl}$. Apesar do aumento ocorrido ao final do período de armazenamento, o pH permaneceu baixo, com valores entre 3,56 e 3,72 (Figura 1). O baixo pH encontrado no abacaxi consiste num importante fator de restrição ao crescimento de microrganismos.

Constatou-se diminuição linear na atividade peroxidásica em razão do tempo. A menor atividade foi observada nas amostras tratadas com $\mathrm{CaCl}_{2} 2 \%$ seguida pelas tratadas com $\mathrm{CaCl}_{2} 1 \%$. Tal comportamento manteve-se até o nono dia, a partir do qual, os frutos controle e os tratados com $\mathrm{CaCl}_{2}$ apresentaram atividade peroxidásica muito próxima (Figura 2). A redução do $\mathrm{pH}$ do fruto, promovida pelo tratamento com $\mathrm{CaCl}_{2}$, possivelmente interferiu na atividade da peroxidase, uma vez que a acidificação do meio conduz à desnaturação reversível da proteína (Lu \& Whitaker, 1974).

O escurecimento oxidativo do tecido está relacionado à ação da polifenoloxidase e da peroxidase (Gonçalves, 2000). Acredita-se que as peroxidases sejam responsáveis pelas mudanças indesejáveis no sabor e textura, além de promoverem o desenvolvimento de coloração escura (Reed, 1975, Burnette, 1977, Hemeda \& Klein, 1990, Clemente \& Pastore, 1998 citados por Brito, 2001). Esperava-se encontrar relação entre a atividade peroxidásica e a coloração da polpa, ou seja, menor escurecimento
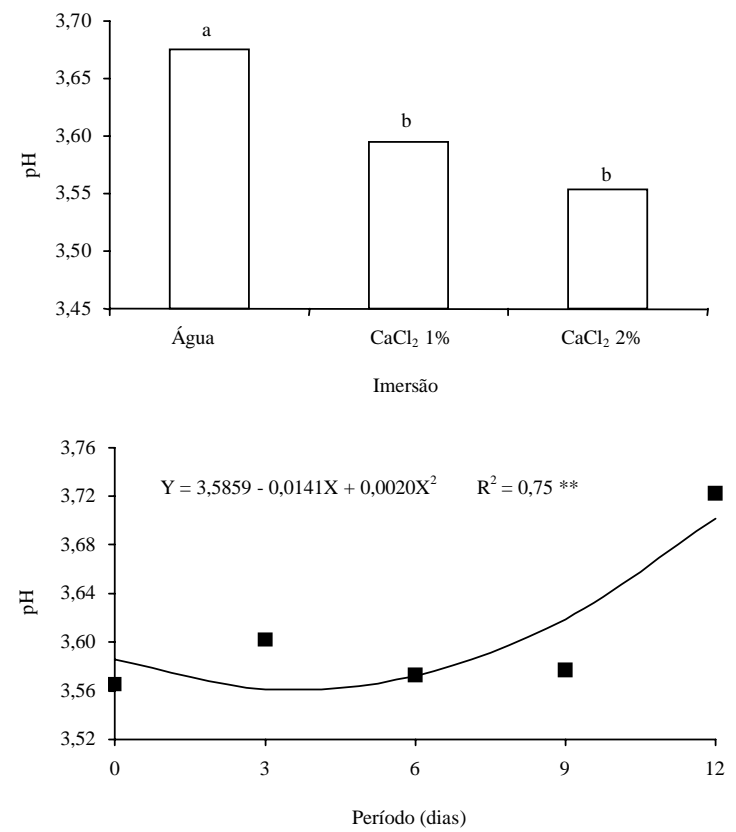

Figura 1. Potencial hidrogeniônico de abacaxi 'Pérola' minimamente processado, submetido a tratamentos de imersão em $\mathrm{CaCl}_{2}$ e armazenamento por períodos até 12 dias a $4 \pm 1^{\circ} \mathrm{C}$ e com pH inicial de 3,68 . As letras minúsculas indicam diferença significativa a $1 \%$ de probabilidade pelo teste de Tukey. 
oxidativo nas amostras com menor atividade peroxidásica. No entanto, os frutos tratados com $\mathrm{CaCl}_{2} 1 \%$ apresentaram, ao 12 o dia de armazenamento, menores valores de $\mathrm{L}^{*}$ e maiores de $\mathrm{a}^{*}$, seguidos pelos frutos submetidos ao tratamento com $\mathrm{CaCl}_{2} 2 \%$ e pelos frutos controle (Figura 3). Tais resultados indicam que o tratamento com $\mathrm{CaCl}_{2}$ interferiu negativamente na coloração da polpa do abacaxi MP, tornando-a mais escurecida.

Os maiores valores de $\mathrm{a}^{*}$ associados aos menores valores de $\mathrm{L}^{*}$ conferem coloração mais escura ao fruto, uma vez que os valores de $\mathrm{a}^{*}$, tornando-se positivos, caracterizam maior contribuição do vermelho à cor, enquanto os menores valores de $\mathrm{L}^{*}$ indicam menor luminosidade. Os valores positivos de $\mathrm{a}^{*}$ foram atingidos somente nas amostras submetidas ao tratamento com $\mathrm{CaCl}_{2} 1 \%$, nas quais também verificou-se diminuição mais acentuada no valor $\mathrm{L}^{*}$, indicando maior escurecimento da amostra. $\mathrm{O}$ menor escurecimento foi constatado nas amostras controle que apresentaram valores de $\mathrm{L}^{*}$ superiores a 65,0 e de a* inferiores a -0,46 até o término do armazenamento refrigerado (Figura 4).

Observou-se aumento linear no teor de sólidos solúveis totais (SST) nos frutos tratados com $\mathrm{CaCl}_{2} 1 \%$ e nos frutos controle, ao passo que os

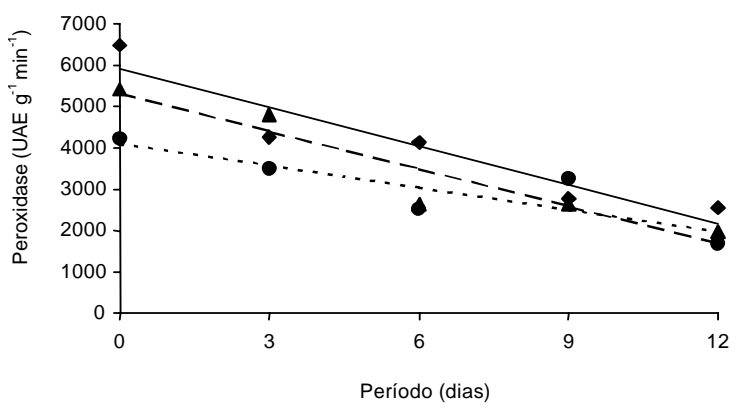

$$
\begin{array}{lll}
\text { - -.- Controle } & \mathrm{Y}=5911,5724-311,7607 \mathrm{X} & \mathrm{R}^{2}=0,89 * * \\
-\mathrm{CaCl}_{2}(1 \%) & \mathrm{Y}=5308,0110-302,0186 \mathrm{X} & \mathrm{R}^{2}=0,89 * \\
\cdots . . . \mathrm{CaCl}_{2}(2 \%) & \mathrm{Y}=4104,0880-177,8568 \mathrm{X} & \mathrm{R}^{2}=0,75 * *
\end{array}
$$

Figura 2. Atividade peroxidásica $\left(\mathrm{UAE} \mathrm{g}^{-1} \mathrm{~min}^{-1}\right.$ ) de abacaxi 'Pérola' minimamente processado submetido a tratamentos de imersão em água (controle) e em $\mathrm{CaCl}_{2} \mathrm{e}$ armazenamento por períodos até 12 dias a $4 \pm 1^{\circ} \mathrm{C}$ e com atividade inicial de $6479,91 \mathrm{UAE} \mathrm{g}^{-1} \mathrm{~min}^{-1}$. **Significativo a $1 \%$ de probabilidade.

Pesq. agropec. bras., Brasília, v. 38, n. 9, p. 1105-1110, set. 2003 submetidos ao tratamento com $\mathrm{CaCl}_{2} 2 \%$ apresentaram teor de SST constante durante todo o período de avaliação (Figura 5). Tal comportamento talvez seja melhor explicado como o resultado da grande variação de SST encontrada no fruto, do que como efeito do tratamento com $\mathrm{CaCl}_{2}$.

Houve pequena variação na acidez titulável em razão do tempo, com valores oscilando entre $0,64 \%$ e 0,74\% de ácido cítrico (Figura 5).

$\mathrm{O}$ tratamento com $\mathrm{CaCl}_{2}$ não interferiu no teor de ácido ascórbico do abacaxi MP, ao contrário de Conway \& Sams (1984), que observaram aumento no teor de vitamina C em maçãs 'Golden Delicious' submetidas ao tratamento com $\mathrm{Ca}(2 \%$ e $4 \%)$ por meio

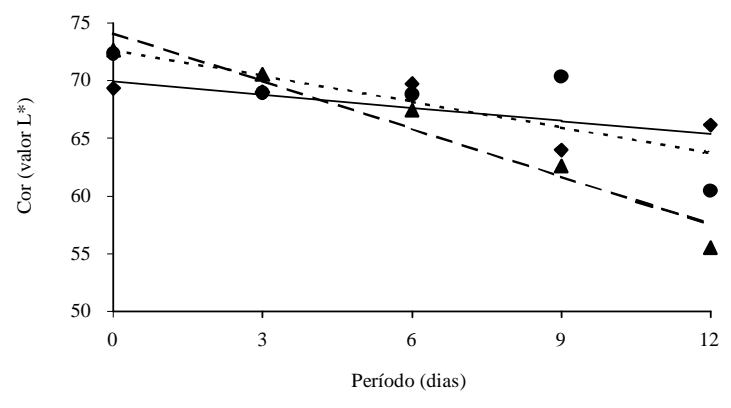

- ---- Controle $Y=69,9307-0,3795 X \quad R^{2}=0,53$ *

$\Delta-\mathrm{CaCl}_{2}(1 \%) \mathrm{Y}=74,1080-1,3832 \mathrm{X} \quad \mathrm{R}^{2}=0,95$ ** - …... $\mathrm{CaCl}_{2}(2 \%) \mathrm{Y}=72.6466-0.7445 \mathrm{X} \quad \mathrm{R}^{2}=0.60$ **

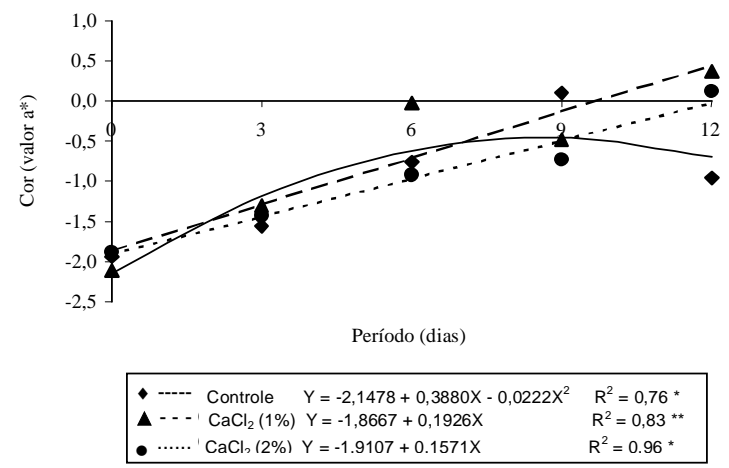

Figura 3. Cor (valores L* e a*) da polpa de abacaxi 'Pérola' minimamente processado submetido a tratamentos de imersão em água (controle) e em $\mathrm{CaCl}_{2}$ e armazenamento por períodos até 12 dias a $4 \pm 1^{\circ} \mathrm{C}$ e com valores iniciais de $71,42\left(\mathrm{~L}^{*}\right)$ e de $-1,97\left(\mathrm{a}^{*}\right) . * \mathrm{e}^{* *}$ Significativo a $5 \%$ e a $1 \%$ de probabilidade, respectivamente. 
de infiltração a vácuo. Constatou-se queda no teor de ácido ascórbico, intensificada ao final do período de avaliação (Figura 5). Os valores observados (39,70 a 50,92 mg de ácido ascórbico por $100 \mathrm{~g}$ de polpa) são superiores ao citado por Usberti Filho et al. (1999). No entanto, Santana \& Medina (2000), caracterizando as alterações bioquímicas durante o desenvolvimento de abacaxis 'Pérola' na região de Cruz das Almas, BA, observaram valores de $50,60 \mathrm{mg}$ por $100 \mathrm{~g}$ de ácido ascórbico em frutos totalmente maduros. Segundo Chitarra \& Chitarra (1990), o teor deste metabólito é fortemente influenciado pelas condições edafoclimáticas.
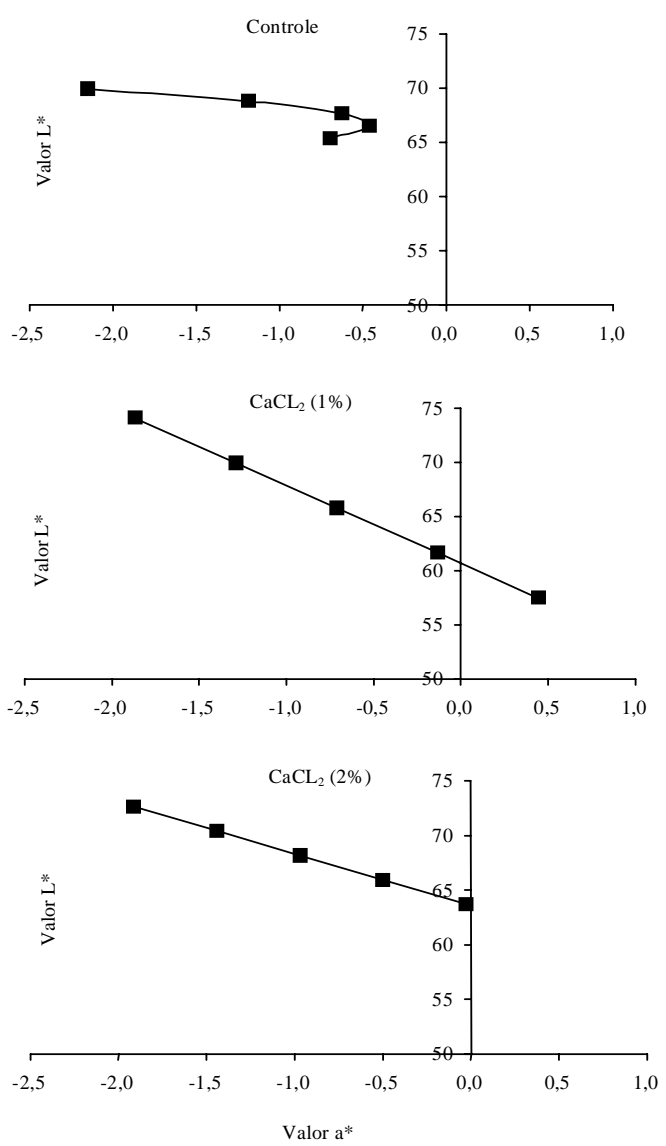

Figura 4. Influência dos valores a* e L* na cor da polpa de abacaxi 'Pérola' minimamente processado submetido a tratamentos de imersão em água (controle) e em $\mathrm{CaCl}_{2} \mathrm{e}$ armazenamento por períodos de $0,3,6,9$, e 12 dias a $4 \pm 1^{\circ} \mathrm{C}$.
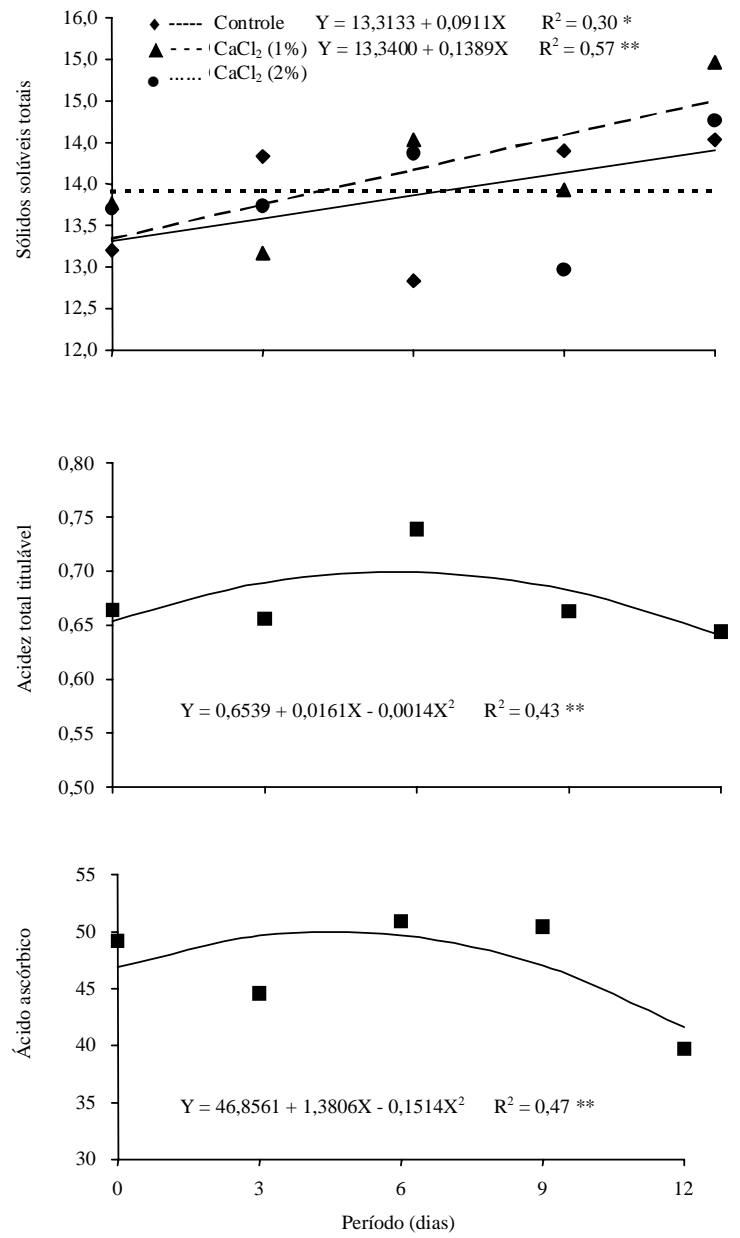

Figura 5. Teor de sólidos solúveis totais ( $\left.{ }^{\circ} \mathrm{Brix}\right)$, acidez total titulável (porcentagem de ácido cítrico) e ácido ascórbico (mg por $100 \mathrm{~g}$ ) de abacaxi 'Pérola' minimamente processado submetido a tratamentos de imersão em água (controle) e em $\mathrm{CaCl}_{2}$ e armazenamento por períodos até 12 dias a $4 \pm 1^{\circ} \mathrm{C}$ e com valores iniciais de $14,1^{\circ} \mathrm{Brix}, 0,67 \%$ de ácido cítrico e 51,5 mg $100 \mathrm{~g}^{-1}$ de ácido ascórbico.

\section{Conclusão}

A utilização de $\mathrm{CaCl}_{2}$ 1\% e 2\% em abacaxi 'Pérola' minimamente processado não proporciona efeito benéfico na manutenção da textura e interfere negativamente na coloração da polpa do fruto.

Pesq. agropec. bras., Brasília, v. 38, n. 9, p. 1105-1110, set. 2003 


\section{Agradecimentos}

À Fundação de Amparo à Pesquisa do Estado de São Paulo (Fapesp), pelo apoio financeiro; à Embrapa - Centro Nacional de Pesquisa Agroindústria Tropical, pelo suporte físico; a Claísa A. Silva de Freitas, pelo auxílio nas análises; a Manoel Alves de Souza Neto e Arthur C. Rodrigues de Souza, pelo auxílio na instalação do experimento.

\section{Referências}

ARTÉS, F.; CASTAÑER, M.; GIL, M. I. Revisión: el pardeamiento enzimático en frutas y hortalizas minimamente procesadas. Food Science and Technology International, London, v. 4, n. 6, p. 377-389, 1998.

BARRET, D. M. Special treatments to maintain product quality. In: ANNUAL WORKSHOP FRESH-CUT PRODUCTS: MAINTAINING QUALITY AND SAFETY, 5., Davis, 1999. [Proceedings...]. Davis: University of California, 1998. Section 5b, p. 6-7.

BOTREL, N.; ABREU, C. M. P. de. Colheita: cuidados e fisiologia pós-colheita do abacaxi. Informe Agropecuário, Belo Horizonte, v. 17, n. 179, p. 33-40, 1994

BRITO, C. A. K. Estudo bioquímico das peroxidases brutas de abacaxi Ananas comosus (L.) Merril: cultivar IAC Gomo-de-Mel e clone IAC-1. 2001. 81 f. Dissertação (Mestrado em Ciência-de-Alimentos) - Universidade Estadual de Campinas, Campinas, 2001.

BUESCHER, R. W.; HOBSON, G. E. Role of calcium and quelating agents on regulation of the degradation of tomato fruit tissue by polygalacturonase. Journal of Food Biochemistry, Trumbull, v. 6, p. 147-160, 1982.

CARVALHO, A. V.; LIMA, L. C. O. Qualidade de kiwis minimamente processados e submetidos a tratamento com ácido ascórbico, ácido cítrico e cloreto de cálcio. Pesquisa Agropecuária Brasileira, Brasília, v. 37, n. 5, p. 679-685, maio 2002

CARVALHO, C. R. L.; MANTOVANI, D. M. B.; CARVALHO, P. R. N.; MORAES, R. M. M. Análises químicas de alimentos: manual técnico. Campinas: Instituto de Tecnologia de Alimentos, 1990. 121 p.

CHITARRA, M. I. F.; CHITARRA, A. B. Pós-colheita de frutos e hortaliças: fisiologia e manuseio. Lavras: ESAL/Faepe, 1990. 293 p.

CONWAY, W. S.; SAMS, C. E. Possible mechanisms by which postharvest calcium treatment reduces decay in apples. Phytopathology, St. Paul, v. 74, n. 1, p. 208-210, 1984.

GONÇALVES, N. B. Abacaxi: pós colheita. Brasília: Embrapa-SCT, 2000. 45 p. (Frutas do Brasil, 5).

IZUMI, H.; WATADA, A. E. Calcium treatments affect storage quality of shredded carrots. Journal of Food Quality, Trumbull, v. 59, n. 1, p. 106-109, 1994.

KHAN, A. A.; ROBINSON, D. S. Hydrogen donor specificity of mango isoperoxidases. Food Chemistry, New York, v. 49, n. 4, p. 407-410, 1994.

KLUGE, R. A.; NACHTIGAL, J. C.; FACHINELLO, J. C.; BILHALVA, A. B. Fisiologia e manejo pós-colheita de frutas de clima temperado. Pelotas: Editora UFPel, 1997. $163 \mathrm{p}$

LU, A. T.; WHITAKER, J. R. Some factors affecting rates of heat inactivation and reactivation of horseradish peroxidase. Journal of Food Science, Chicago, v. 39, n. 6, p. 1173-1178, 1974

LUNA-GUZMÁN, I.; CANTWELL, M.; BARRET, D. M. Fresh-cut cantaloupe: effects of $\mathrm{CaCl}_{2}$ dips and heat treatments on firmness and metabolic activity. Postharvest Biology and Technology, Amsterdam, v. 17, n. 3, p. 201-213, 1999.

MANICA, I. Fruticultura tropical - 5: abacaxi. Porto Alegre: Cinco Continentes, 1999. 501 p.

MIGNANI, I.; GREVE, L. C.; BEN-ARIE, R.; STOTZ, H. U. ; LI, C.; SHACKEL, K.; LABAVITCH, J. The effects of $\mathrm{GA}_{3}$ and divalent cations on aspects of pectin metabolism and tissue softening in ripening tomato pericarp. Physiologia Plantarum, Copenhagen, v. 93, n. 1, p. 108115, 1995.

POOVAIAH, B. W. Role of calcium in prolonging storage life of fruits and vegetables. Food Technology, Chicago, v. 40, n. 1, p. 86-89, 1986.

SANTANA, F. F.; MEDINA, V. M. Alterações bioquímicas durante o desenvolvimento do fruto do abacaxizeiro 'Pérola'. Revista Brasileira de Fruticultura, Jaboticabal, v. 22, p. 53-56, 2000. Número Especial.

USBERTI FILHO, J. A.; SIQUEIRA, W. J.; SPIRONELLO, A.; TANAKA, M. A. S.; SIGRIST, J. M. M.; MARTINS, A. L. M. ; BORTOLETTO N.; TSUHAKO, A. T.; GUSHIKEN, A. Abacaxi gomo-demel. Campinas: Instituto Agronômico, 1999. 5 p. Disponível em: <http://200.136.175.13/homeiac/produtos/ abacaxi.htm>. Acesso em: 19 nov. 1999. 